\title{
Deficit in Active Avoidance Learning in Rats Following Penicillin Injection into Hippocampus'
}

\author{
LEONARD W. SCHMALTZ ${ }^{2}$ \\ University of Michigan, Ann Arbor, Michigan, U.S.A.
}

(Received 7 November 1970)

\begin{abstract}
SCHMAltz, L. W. Deficit in active avoidance learning in rats following penicillin injection into hippocampus. PHYSIOL. BeHAV. 6 (6) 667-674, 1971.--Penicillin was found to cause epileptiform (spike) activity when injected into the hippocampus of male rats. Animals so prepared were found to be severely impaired in the acquisition of a two-way active avoidance task. Animals with bilateral hippocampal destruction produced by aspiration and animals receiving an antibiotic, sodium sulfadiazine, which did not cause epileptiform activity learned the task as quickly as did unoperated animals. In a second study, rats were trained on the two-way task and then subjected to penicillin injection. They rapidly reached the preoperative criterion showing significant amounts of retention. The fact that they were able to perform the avoidance response quite readily suggested that the impaired animals in Experiment 1 were not suffering from some basic sensory or motor loss.
\end{abstract}

THERE is ample evidence that penicillin applied to the cortex of various animals result in epileptiform activity as evaluated with electrocorticograms $[4,5,9,15,16]$. The present study asked whether this drug could significantly influence behavioral processes as well. Penicillin was injected into the hippocampus of male rats and the animals were tested for acquisition of a two-way active avoidance problem. Rats with bilateral hippocampal destruction produced by aspiration have been found on two occasions to acquire this task faster than unoperated and control animals [2, 7]. The two-way task, therefore, seemed particularly appropriate for assessing the effects of chemical disruption of the hippocampus. By including groups with hippocampal destruction produced by aspiration, it was also possible to compare directly the effects of aspiration lesions with those resulting from chemical disruption. Several authors have proposed that seizure activity within the hippocampus is in part behaviorally equivalent to a functional ablation $[3,6,14]$.

In a second part of the study reported here, rats were trained on the two-way task preoperatively and then subjected to penicillin injection into hippocampus. It was felt that such a procedure would help to clarify the nature of the deficit found in the first part of the study.

\section{Animals}

$$
\text { METHOD-EXPERIMENT } 1
$$

The animals were 83 male albino rats from the Spartan Animal Farms (Haslett, Michigan) weighing 325-375 $\mathrm{g}$ at the start of the experiment. They were divided into eight groups.

\section{Operative and Electrophysiological Procedures}

Animals in Groups I-VII were anesthetized with a $15 \%$ urethane solution $(1.75 \mathrm{~g} / \mathrm{kg}$ i.p.). All groups contained 10 animals, with the exception of Group II, which contained 13 animals. Animals in all groups were given a recovery period of 8 days.

Group I (Unoperates receiving urethane). This group served as an unoperated control group. The animals remained in a Kopf stereotaxic instrument for approximately $5 \mathrm{~min}$ and were then removed.

Group II (Bilateral hippocampal destruction). After approximately $5 \mathrm{~min}$ in the stereotaxic instrument, the animals were removed and subjected to bilateral hippocampal destruction by aspiration. The general operative procedure has been described in detail previously [2].

Group III (Unilateral penicillin group). A midline incision was made in the scalp and the skull scraped free of fascia. A small circular hole was drilled in the skull $5 \mathrm{~mm}$ posterior to bregma and $5 \mathrm{~mm}$ lateral to midline.

Twenty gauge hypodermic tubing insulated except at the tip with Form-Var (General Electric Company) served as a combination cannula-electrode. The cannula had been previously loaded with S-R penicillin (Parke, Davis \& Co., Detroit, Michigan). The loading process was as follows. A small amount of penicillin was spread evenly and thinly on glassine paper. Tamping the insulated cannula on the spread penicillin 20 times with approximately equal force caused a small plug to form in the end of the cannula. Twenty such plugs were weighed and found to have a mean weight of

${ }^{1}$ This research is based upon a dissertation submitted by the author in partial fulfilment of the requirements for the Ph.D. degree at the University of Michigan. The author gratefully acknowledges the assistance and encouragement of his doctoral committee: Robert L. Isaacson, Edward L. Walker, Stephen Glickman and Edward F. Domino.

'Present address: Department of Psychology, University of Wisconsin, Charter at Johnson St., Madison, Wisconsin 53706. 
$0.4 \mathrm{mg}$. No plug weighed less than $0.3 \mathrm{mg}$ nor more than $0.5 \mathrm{mg}$. A thin layer of bone wax was applied to the tip of the loaded cannula to prevent diffusion as it was lowered into the brain.

All electrophysiological recordings were made with a Grass Model 7 polygraph. The specific procedures used in collecting the electrophysiological data are available elsewhere [10]. Briefly, the cannula was lowered $5.5 \mathrm{~mm}$ below dura into the hippocampus and samples of activity were taken for $30 \mathrm{~min}$, the cannula in the hippocampus serving as an electrode. A 20-gauge needle cleaner was used to force the penicillin plug from the cannula. Following this, samples of activity were taken every $20 \mathrm{~min}$ for a period of $2 \mathrm{hr}$. After completion of the recording session, the cannula was removed from the brain and the scalp closed with silk sutures.

Group IV (Unilateral sodium sulfadiazine). The animals in this group were subjected to the same procedures as the animals in Group III with the exception that the cannula was loaded with sodium sulfadiazine, an antibiotic recommended by Dr. Lamar Roberts (personal communication) which pilot studies indicated did not cause hippocampal epileptiform activity. Twenty plugs of this drug formed by tamping the cannula 7 times were weighed and found to have a mean weight of $0.4 \mathrm{mg}$. No plug weighed more than $0.5 \mathrm{mg}$, nor less than $0.3 \mathrm{mg}$. Five of the animals in this group were given this dosage.

The remaining five animals were given a double dose of sodium sulfadiazine. This was prepared by tamping the cannula 18 times. Twenty plugs so prepared had a mean weight of $0.8 \mathrm{mg}$. No plug weighed more than $0.9 \mathrm{mg}$ nor less than $0.7 \mathrm{mg}$.

Group $V$ (Unilateral penicillin combined with unilateral hippocampal destruction). Animals in Group $V$ were prepared as those in Group III with the only exception being that after the completion of the recording session, the hippocampus contralateral to the cannulated side was removed by aspiration. This group was included because a preliminary study indicated that this procedure produced a severe impairment on the two-way task. Electrophysiological recordings taken after the period of behavioral testing also indicated that removal of the contralateral hippocampus resulted in more extensive epileptiform activity.

Group VI (Unilateral neocortical penicillin combined with unilateral hippocampal destruction). Group VI animals were prepared as those in Group V. The cannula, however, was only lowered $0.5 \mathrm{~mm}$ below dura and the plug forced into the posterolateral neocortex overlying the hippocampus.

Group VII (Unilateral sodium sulfadiazine combined with unilateral hippocampal destruction). The procedures employed for this group were the same as those for Group IV. Five animals received the single dose of sodium sulfadiazine and five the double dose. In addition, the contralateral hippocampus was removed by aspiration in all animals in this group.

Group VIII (Unoperates not receiving urethane). This group was an unoperate group, receiving no urethane, and was not placed in the stereotaxic instrument.

\section{Recovery Period}

The overwhelming majority of the animals had recovered from the urethane anesthetic after $24 \mathrm{hr}$. Three hr after the completion of surgery, $5 \mathrm{~cm}^{3}$ of warm saline were injected I.P. During the recovery period, all animals' eyes were kept moist with mineral oil and cleaned repeatedly with moist gauze sponges. For five days postoperatively, an antibiotic (Tetracycline) was added to the drinking water of all operated animals. All animals were weighed each day during the recovery period and throughout the period of behavioral testing. Following a period of initial weight loss, animals in all groups gained weight rapidly and at the time behavioral testing began only two animals had not reached or surpassed their pre-operative levels. Throughout the period of behavioral testing, the animals gained weight normally with no differential weight gains in any particular group. Three of the 13 rats in Group III did not recover from the anesthetic and died in 3-4 days.

\section{Behavioral Testing}

The avoidance chamber was constructed of wood and painted a uniform black color. It was 16 in. in length and 5.75 in. in width. The floor consisted of brass rods 0.5 in. apart. A guillotine door divided the chamber into two equal compartments. When the door was raised, a barrier extended 1.25 in. above the grid floor.

The sides of the chamber were 8 in. high. Positioned 6.5 in. above the grid floor on one side wall of each chamber was a $6 \mathrm{~W}$ bulb. The bulbs were located in the center of each compartment.

Three simultaneous events constituted the CS (conditioned stimulus): (1) the guillotine door was raised; (2) the light in the unsafe compartment (the compartment occupied by the animal) went off and the light in the safe compartment came on; and, (3) a burst of white noise $\left(63 \mathrm{~dB}\left(0.002 \mathrm{dynes} / \mathrm{cm}^{2}\right)\right)$ provided by a Grason-Stadler noise generator (Model 901B) fed through a 4 in. speaker was initiated. The speaker was located at a center point $15 \mathrm{in}$. above and $15 \mathrm{in}$. behind the avoidance chamber.

The CS remained in force for $10 \mathrm{sec}$. If the animal had not made the avoidance response in this period, the US (unconditioned stimulus) was initiated. The US consisted of $0.8 \mathrm{~mA}$ shocks delivered in $0.5 \mathrm{sec}$ pulses, $1 / \mathrm{sec}$, produced by a Grason-Stadler shock generator (Model E1064GS). The animal was shocked until it made the escape response. At this point, the guillotine door was lowered and the white noise terminated. The intertrial interval was $30 \mathrm{sec}$. At the end of this period, another trial began and the animal was required to return to the original compartment. Twenty such trials were given per day.

The following response measures were recorded by the experimenter for each trial: (1) whether the animal moved to the other side before US onset (an avoidance response) or required the initiation of the US (an escape response); (2) the avoidance or escape latency, whichever was appropriate; and, (3) the number of shocks delivered before the escape response occurred.

In order to reach the behavioral criterion, an animal had to average 18 or more avoidance responses on 2 consecutive days. If an animal had not reached criterion after 400 trials, behavioral testing was terminated.

\section{Post-behavioral EEG Session}

All animals receiving chemical plugs were anesthetized with urethane within $24 \mathrm{hr}$ after they reached criterion or had completed 400 trials. The electrode used to record from the cannulated hippocampus or the cannulated neocortex (Group VI) was the empty cannula with no bone wax over the tip. The same stereotaxic coordinates were employed that had 
been used previously. Samples of activity were taken approximately every $20 \mathrm{~min}$ for a period of $3 \mathrm{hr}$ after the cannula was lowered into the hippocampus. Two animals (one each in Groups III and VII) died, presumably due to the anesthetic, before the recording session could begin.

\section{METHOD-EXPERIMENT 2}

\section{Animals}

The animals were the unoperated rats (Group VIII) and the unoperated rats receiving urethane (Group I) of Experiment 1 .

\section{Surgery}

Two or three days after the unoperated rats in Experiment 1 reached criterion, they were anesthetized with sodium pentobarbital $(50 \mathrm{mg} / \mathrm{kg}$ i.p.) and prepared as those animals in Group V of Experiment 1 (unilateral penicillin combined with destruction of the contralateral hippocampus). There were no electrophysiological recordings taken either before or after behavioral testing in Experiment 2.

\section{Recovery Period}

All animals recovered from the sodium pentobarbital anesthetic in from 2 to $3 \mathrm{hr}$. They lost virtually no weight and continued to gain weight during the recovery period of 8 days.

Two animals died 3-4 days after surgery. Inspection of the brains revealed that extensive infection had occurred bilaterally. Two animals died during surgery presumably due to the anesthetic.

\section{Behavioral Testing}

At the completion of the recovery period, the animals were tested for retention of the avoidance task. The same procedures were used here as preoperatively. The animals were tested until they reached the preoperative criterion.

\section{HISTOLOGICAL EVALUATION}

All animals were intracardially perfused immediately after completion of the postbehavioral EEG session with $0.9 \%$ saline followed by $10 \%$ formalin and the brains removed. Animals of Group II (bilateral hippocampals), who had no electrophysiological records taken, and the animals of Experiment 2 were perfused shortly after reaching the behavioral criterion. Following infiltration and embedding with paraffin, serial sections of $20 \mu$ thickness were made throughout the lesioned areas. As a general procedure, every twentieth section was retained, stained with thionin, and mounted. Some selected slides were stained with Mallary's PTAH stain as modified by Hicks and D'Amato (personal communication).

The hippocampal lesion produced by aspiration in each brain was reconstructed on representative diagrams of the rat brain adapted from the atlas by DeGroot [1] at seven regularly spaced levels throughout the lesioned areas. Superimposed on these representative diagrams were $0.5 \mathrm{~cm}$ squares. By counting the number of squares covered by each lesion, it was possible to compute a numerical index of the amount of total brain damage sustained by the animal and the extent of damage to specific structures within the brain. The hippocampal lesions in the present study were both quantitatively $(0.5 \mathrm{~cm}$ squares) and qualitatively similar to those produced in earlier studies [10-12].

Brain damage in the lesioned animals was limited to four structures-the posterior neocortex, the corpus callosum, the fimbria, and the hippocampus. A separate analysis of variance of the units destroyed was computed for each of the four structures listed. None of the four analyses approaches statistical significance. This, of course, indicates that no one group sustained substantially greater or less damage to any particular structure. In computing these analyses, the left and right sides of animals in Group II (bilateral hippocampals) were considered as separate groups. An analysis of variance of total brain damage also failed to produce statistical significance.

The cannula tracts were visible in all brains and in every case the cannula clearly penetrated the hippocampus. While there was some variability from animal to animal, in the majority of cases the cannula entered the more posterior portions of the hippocampus where it is at its largest extent in the rat (see Fig. 1). In no case did the cannula enter the thalamus or the lateral ventricle.

It was possible to distinguish the original penetration from the second one due to the presence of proliferating glial cells around the site of original penetration. In addition, in many animals there were trapped blood cells around the site of second penetration.

Yellow non-nuclear material was found in the hippocampus of many of the animals in both the penicillin and sodium sulfadiazine groups. The most obvious explanation is that this material was a remnant of penicillin or sodium sulfadiazine or, possibly, the bone wax. The color and structure were not that of blood cells. In some instances, this yellow material could be seen inside phagocytes.

$$
\text { RESULTS-EXPERIMENT } 1
$$

\section{EEG Recordings}

In brief résumé: The penicillin always produced epileptiform (spike) activity after it had been in the hippocampus for approximately $10 \mathrm{~min}$ (Fig. 2). The spiking continued undiminished during the entire $2 \mathrm{hr}$ recording session. Animals in which the penicillin plug was deposited into the posterolateral neocortex overlying the hippocampus also showed epileptiform (spike) activity which began approximately 5 min after injection and continued for the duration of the 2-hr recording session.

None of the animals receiving sodium sulfadiazine showed spike-like activity during the postinjection recording session which lasted at least $2 \mathrm{hr}$. After an initial period of depression, the records returned to their preinjection state. Ten of these animals received $0.4 \mathrm{mg}$ of sodium sulfadiazine while ten received $0.8 \mathrm{mg}$. The electrophysiological recordings of these two groups were indistinguishable.

The electrophysiological recordings taken after the period of behavioral testing showed that the hippocampus and neocortex previously injected with penicillin continued to exhibit epileptiform activity for periods of as long as a month after the injection (Fig. 3). There were obvious spikes and abnormal activities in the records from these animals. It was impossible to distinguish the EEG records of the animals with and without destruction of the contralateral hippocampus. The animals in Group V, for example, did not show spikes more often or in greater amplitude than did those in Group III. The animals previously injected with sodium sulfadiazine, on the other hand, did not show such 

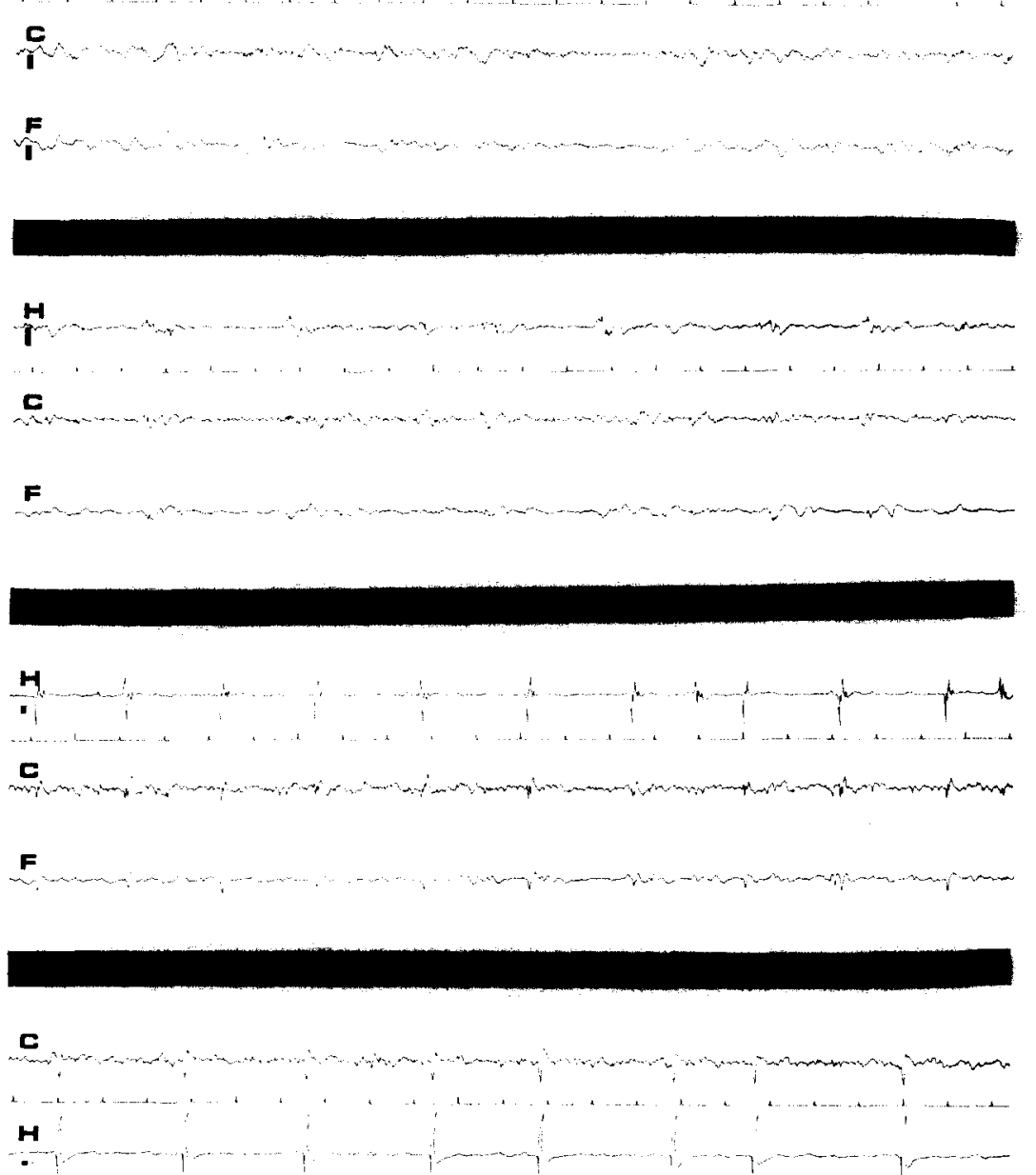

$\boldsymbol{F}$

FIG. 2. EEG records of an animal who had penicillin injected into the hippocampus. ( $F=$ frontal cortex, $C=$ contralateral cortex, $\mathrm{H}=$ hippocampus.) In this and in Fig. 3 the records labeled $\mathrm{C}$ and $\mathrm{F}$ were taken from silver disc electrodes attached to the skull with denture adhesive. The frontal electrode was positioned $1 \mathrm{~mm}$ anterior to the coronal suture equidistant from the temporal ridge on either side. The contralateral electrode was positioned $2 \mathrm{~mm}$ posterior to the coronal suture and equidistant from the midline suture and the temporal ridge. It was always placed on the skull contralateral to the side of injection. Uppermost record: before cannula lowered into hippocampus. Second reciord: seconds before penicillin plug forced into hippocampus. Third record: $1 \mathrm{hr}$ after plug in hippocampus. Bottom record: $2 \mathrm{hr}$ after plug in hippocampus. The pulses on the time-tracing occur every second. The calibration lines under $F$ and $C$ in the top record represent $50 \mu \mathrm{V}$. The calibration lines under $H$ in the bottom three records represent $0.5 \mathrm{mV}$.

abnormalities. The hippocampal records from these subjects were very much like those taken before the period of behavioral testing began.

\section{Behavioral Results}

Figure 4 shows the mean number of avoidance responses made by the various groups during the avoidance training. The high number of avoidance responses shown for Day 1 of training is partially due to the fact that a number of animals in all groups made spontaneous crossings, that is, crossings before any shocks had been given. These were presumably due to the natural exploratory tendencies of the rats. An analysis of variance of the number of such spontaneous crossings failed to reach statistical significance.

Table 1 presents the mean number of trials which the eight groups of animals took to reach the behavioral criterion. 